\title{
Drugs and Supplements in Amateur Boxing: Pugilistic Amateurism and Ideologies of Performance
}

\section{Christopher R. Matthews \& Mark Jordan}

This research, which is based on the thoughts and experiences of coaches, athletes, officials and others involved in amateur boxing, explores the use of recreational drugs, supplements and performance-enhancing drugs in the sport. After providing some context through a discussion of ideologies that shape elite sport, some key methodological issues are briefly described. The findings explore the manner in which ideologies of performance are shaped in relation to the notion of 'pugilistic amateurism'. In this way, the paper maps out a theoretical scaffold that can be used to understand the manner in which 'old school' training methods and participation in sport align with 'traditional' understandings of work-class manhood to produce an ideological tension with a win-at-all-costs mentality. This sheds light on the ways that boxing gyms might be understood as havens where drugs use can be resisted at the same times as potentially positive behaviours can be learned. 


\section{Sporting Cultures, Performance Ideology and Drug Use}

The increasingly commodified and professionalised world of elite sport is saturated in an "athletic achievement and performance improving ideology" (Stewart and Smith 2010, 195). Such a claim is substantiated by social scientific research across five decades that highlights the damaging effects of the political economy that pervades the majority of professional sports (Brohm, 1976; Hargreaves, 1986; Maguire, 2004; Matthews and Maguire, 2019; Sugden and Tomlinson, 2002; Young, 1993). Such arguments are made even more robust when they are integrated with empirical and theoretical explorations of the often taken-for-granted behaviours embedded in elite competition (Hughes and Coakley, 1991; Matthews and Channon, 2016, 2017; Messner, 1990; Young et al, 1994).

Of particular salience, in this regard, is Hughes and Coakley's (1991) classic paper examining the damaging consequences of over-conformity to normative understandings of sporting performance which can, under reasonably common conditions, lead athletes to forsake their physical and mental wellbeing in the pursuit of excellence. When this broad social context is combined with increases in the medicalisation and scientisation ${ }^{1}$ of sport (Hoberman, 1992; Malcolm, 2016; Waddington, 2016), athletes' recourse to drug use to gain competitive advantage becomes less a matter of personal (im)morality and more a logical and perhaps necessary dimension of their participation (Dimeo, 2007, 2010; Houlihan, 2002; Johnson, 1990; Miah, 2004; Pappa and Kennedy, 2012; Waddington and Smith, 2009).

While this is an indictment that many will find saddening, it is a reality that lead Stewart and Smith $(2010 ; 195)$ to conclude, in their research exploring Australian elite cycling, that:

The fact that some unnamed cyclists were prepared to do all that it takes to secure a competitive edge was indicative of an ideology substantially different from the one promulgated by politicians, sports officials and journalists. It had little to do with developing character, building the sport, or becoming healthier, but a lot to do with breaking through performance barriers.

While the world of cycling has its own unique history and legacy of doping scandals (Schnieder, 2007), Stewart and Smith (2010) highlight an important gap between the values and meanings that supposedly frame participation in sport and the cultural realities of performance-orientated competition.

Indeed, the often-mythologised historical origins of what Maguire (2004) calls the 'sports-industrial-complex' in an amateur ethos of 'fair play' and 'pure' competition (Holt, 1989) can still provide a powerful discursive whitewash to obscure such realities behind a 'ludic veneer' (Matthews and Channon, 2016). For as Tomlinson $(2005$; 47) argues of the Olympics Games, if something transcendental and even spiritual is believed to characterise sport this serves to move the "grubby materialism of everyday life" beyond critique. Furthermore, this process can underpin assumptions that doping results from the moral failure of 'cheating', 'deviant' athletes, rather than as being a product of the social and cultural conditions that frame contemporary sports (Dimeo, 2007; Houlihan, 2002; Hughes and Coakley, 1991; Maguire, 2004; Waddington and

${ }^{1}$ Medicalisation and scientisation are the processes whereby ideas from medical and scientific understandings of the world increasingly dominate social interactions and the ways in which people interpret everyday life. 
Smith, 2009; Møller, Waddington, and Hoberman, 2016). It is within this ideological tension that sports organisations, sponsors, coaches and athletes operate on a daily basis.

Academic research has contributed to this understanding by detailing the ways doping is quantified (Lentillon-Kaestner and Ohl, 2010) and the pervasiveness, frequency and type of drug and supplement use (Morente-Sanchez, Mateo-March and Zabala, 2013; Lun, Erdman, Fung and Reimer, 2012; Strano Rossi and Botre, 2011). Alongside such works, social scientists have sought to unpack the structural, economic and cultural processes that shape drug use in sport. Such research has drawn attention to the complex sociological and historical development of doping (Beamish and Ritchie, 2005; Coomber, 2014; Dimeo, 2007; Møller, Waddington, and Hoberman, 2016), the precarious and often powerless positions of athletes (Waddington and Smith, 2009) and the lack of coherent logic underpinning the current 'war on drugs' (Beamish and Ritchie, 2004; Coomber, 2014; Houlihan, 2002; Sluggett, 2011; Waddington et al, 2014).

Following a reasonable proposition that the presence of financial rewards can act as a key factor in increasing the likelihood of athletes seeking performance-enhancement via drug use, the vast majority of research in the area has focused on professional athletes. Yet, as Ohl et al (2013) neatly describe, young athletes are 'professionalised' in part through their socialisation into the culture of elite sports. This argument opens a window into the process whereby amateur athletes who seek future success in professional sport, are prepared for sporting cultures dominated by a performance ideology that can serve to normalise drugs use (Henning and Dimeo, 2018). Furthermore, there is increasing evidence that performance-enhancing drugs are used by people without serious sporting ambitions (Henning, 2015; Laure and Binsinger, 2007) and various 'at risk' populations (Baron, Martin and Magd, 2007). And, while usually poorly informed, narratives about anti-doping have "bleed into the everyday practices of the non-elite runner" (Henning, 2014, 494) and similar levels in other sports (Henning and Dimeo, 2018; Striegel, Simon and Frisch, 2006).

So, despite the lack of money in the lower levels of sport, we would argue that this 'trickle down' effect follows the 'professionalisation' of amateur sport and the increasing pervasiveness of the culture of performance across the majority of sports worlds. Indeed, Waddington and Smith (2009) suggest that alongside the medicalization of life and the commercialisation and politicisation of sport, this process of de-amateurisation plays a crucial role in the development of doping as a social problem. Greaves and Llewellyn (2014) go further by evidencing amateurism as an organising principle for prevailing moralistic arguments against drug use. They note the irony that sits at the heart of this process; "as the IOC moved to keep sport pure by launching a war on doping, they simultaneously dismantled amateurism, the very idea that gave rise to the issue" (Greaves and Llewellyn, 2014, 850).

While the moral tenets embedded in notions of amateurism might feel oddly out dated in the world of modern sport, the legacy of such ideas still act to shape the enforcement of anti-doping policies (Beamish and Ritchie, 2004; Greaves and Llewellyn, 2014). And it is not a big stretch to imagine that such moralising is still a central feature of ways that sporting insiders seek to maintain a positive public perception of sports participation, especially as a vehicle for the socialisation of young people (Crabbe, 2000; Jump, 2017). Indeed, amateur boxing, one of the only sports that expressly marks itself as still being situated within this amateur ethos, exists as a sporting institution where professionalism is, in important ways, resisted. Boxing gyms, therefore, might reasonably be expected to be interesting social spaces within which to further explore these ideas. 


\section{Cultures of Performance, Amateurism and Amateur Boxing}

While there has been a sustained examination of boxing in relation to class (de Garis 2000; Fulton 2011; Heiskanen 2012; Jefferson 1996; Rhodes 2011; Sugden 1996; Wacquant 2004; Woodward 2007) and gender (Channon and Matthews, 2015; Halbert 1997; Heiskanen 2012; Lafferty and McKay 2004; Lee 2009; Matthews, 2014, 2016; Matthews and Channon, 2019; Mennesson 2000; Paradis 2012; van Ingen 2011; van Ingen and Kovacs 2013; Woodward 2007) it appears very little, if any, has explicitly focused on drug and supplement use ${ }^{2}$. Within key academic books about boxing, discussions of drug use are either non-existent or limited to passing contextual notes that situate gyms in relation to the recreational drug trade that is prevalent in the wider community. Yet, scattered within research on the sport are important empirical and theoretical points that, when taken together, offer a conceptual scaffold that can be employed to frame some initial thoughts on the topic. While this framework is employed within the present study to help examine drug use, we hope to show that it offers further explanatory potential for those interested in exploring boxing spaces.

Much of boxing, like most contemporary Western sports cultures, is shaped by a resultsbased performance ideology. As such cultures become increasingly prominent within the elite level of the sport it is reasonable to expected a 'trickle down' effect in amateur boxing. Indeed, shifts towards scientisation and medicalization that are embedded in this performance efficiency model of sport (Maguire, 2004) can be evidenced in the increasingly professionalised nature of amateur boxing. For example, GB Boxing, which coordinate amateur boxing at a national level in Great Britain was established in 2008, now has a permanent base at the England Institute of Sports facility in Sheffield, UK. They employ, among other staff, a Performance Director, a Head of Performance Sport, Physiotherapists, Performance Analysts and various other roles related to sports science. Such relatively recent developments demonstrate the manner in which parts of boxing are increasingly aligning with contemporary understandings of sports performance.

Yet, the history and sociology of the sport has led some to explore boxing gyms, and the cultural narratives lived out within them, as potentially and actually resistant to social change (Heiskanen 2012; Matthews, 2014, 2016; Sugden, 1996; Woodward, 2007; Wacquant, 2004). In this regard, Wacquant (2004) discusses the ghettoised site where he conducted his research:

By contrast to this hostile and uncertain environment, and despite its severe dearth of resources, the Boys and Girls Club constitutes an island of stability and order where social relations forbidden on the outside become possible again. (Wacquant, 2004, 26, my emphasis)

Despite the notoriety of Wacquant's work, Woodward's (2007) and Matthews's (2014, 2016) research provides a more considered theoretical account of how boxing clubs might exist in some important ways as isolated from broad social shifts. In particular, they focus on the manner in which stoic, physically powerful and aggressive iterations of working-class masculinity, which are less commonly seen within society more broadly, can be forged and embodied through routine performances inside and around the ring. And as Matthews $(2016,329)$ argues, such pugilistic male preserve offers,

\footnotetext{
2 Wadler $(2009,542)$ provides an overview of doping in boxing, but oddly says very little about the sport and instead offers nothing more than a conservative retelling of tired old narratives about doping being "a violation of the publics trust".
} 
"boxers a space in which to experience a narration of manhood that is relatively removed from late modern life".

The symbolic and often geographic connection between boxing and lower socioeconomic status or otherwise under-privileged communities tends to align with and reinforce narratives about the importance of working hard and not cutting corners as the main pathways to pugilistic success (Sugden, 1996; Woodward, 2007; Wacquant, 2004). In this way, bodily performances of 'gritty', hardened and instrumental understandings of masculinity are commonplace (Matthews, 2014, 2016; Woodward, 2007). Alongside this, ideas about gender and class often align to maintain the social significance of 'old school'3, rigorous and sometimes tortuous training methods. As a result, the repetitive drilling of basic techniques, arduous physical training and simple ideas about nutrition largely dominate boxing spaces (Paradis, 2012; Matthews, 2014, 2016; Wacquant, 2004; Woodward, 2007) and such practices can be taken as empirical examples of an ideological opposition to the latest ideas informed by the performanceorientated sports sciences (Maguire, 2004).

Furthermore, lessons in morality, sportsmanship and work-ethic that are frequently taught and learned inside the ring are often understood as more important than winning (Jump, 2017; Matthews, 2019; Wacquant, 2004). We would argue that when taken together these points evidence a relatively unique 'pugilistic amateurism' which informs both boxers orientation to their bodies and participation in the sport. And although Wright (2018) highlights the important place that 'white collar' boxing might occupy in partly undermining the historical connection to the working-classes and a pugilistic version of amateurism by condensing the training commitment that competing boxers must undertake, it is still fair to expect such ideologies to shape life in most boxing clubs.

It appears then, that pugilistic spaces offer the possibility to produce and support gym denizen's attempts to resist often taken-for-granted ideologies that dominate life outside of the gym. This can be understood, in part, via a reading of boxing spaces as existing in important ways as potentially isolated from broad social shifts (Matthews, 2014, 2016; Woodward, 2007). Within these pugilistic havens, 'traditional' understandings of manhood, class, the body and sport participation can be lived out, embodied and recreated (Paradis, 2012; Matthews, 2014, 2016; Wacquant, 2004; Woodward, 2007). And, as such, when considering social scientific research on boxing as a whole, it is possible to distil key evidence and important theoretical scaffolding that points to the manner in which boxing spaces, and the social interactions normalised within them, could act to slow the progress of performance ideologies filtering into the sport.

While this symbolic framing of boxing does not perfectly echo the historical origins of amateurism, which are embedded an upper-class rejection of professionalism in favour of 'gentlemanly' competition for the 'love' of participation (Alison, 2001), there is certainly an important conceptual and empirical resonance. In particular, the notion of amateur boxing as a vehicle for the socialisation of young people, most usually boys, into respectful and hard-working adults, sits in a logical and ideological tension with the win-at-all-costs narratives that often accompany performance-orientated sport (Hughes and Coakley, 1991; Maguire, 2004). Yet, no research has explicitly explored the role of this pugilistic amateurism in shaping life inside and around the ring, especially in relation to the manner it might help athletes and coaches oppose performance ideologies. What is more, while various sports have been explored in relation to drugs and supplement usage, boxing has yet to be considered in this regard. And despite some

\footnotetext{
3 Taken here and commonly within boxing gyms to mean traditional training methods and sensibilities employed by previous generations of coaches and athletes
} 
relatively recent contributions little is known more broadly about what athletes understand in relation to drug and supplement use and how they think about such issues (Johnson, Butryn and Macucci, 2013; Pappa and Kennedy, 2012; Sas-Nowosielski, and Swiatkowske, 2007).

Following a brief discussion of methods the remained of this paper focuses on filling these gaps in the literature by considering the following questions; How do those connected to boxing think about and consider drug and supplement use in sport? And what ideas do they draw on to make sense of these understandings? In so doing this paper provides a meaningful contribution in that it 1) fills an empirical gap within the study of boxing and drug use in sport and 2) demonstrates the utility of a theoretical framing of the sport as in important ways a haven where 'traditional' understandings of participation of sport can be experienced. In particular, the focus is on the notion of a pugilistic amateurism and the ways in which it can create an ideological tension between the everyday practices that dominate gym life and broad shifts in performanceorientated sport.

\section{Method}

This study was funded by England Boxing; the governing body for amateur boxing in England. It was commissioned as a small-scale exploration of drug and supplement use in the sport. It is based on the experiences of those who participate in, and are connected to, amateur boxing in England. Based on the previous experiences of the lead author and insights from others who have conducted similar immersive research (Paradis, 2012; van Ingen, 2011; Wacquant, 2004; Woodward, 2008), the research team expected to encounter various methodological difficulties when attempting to explore issues around drugs use in boxing. In particular, a distrust of authority (in the form of law enforcement or sporting governance), a motivation to protect privacy and a general unwillingness to discuss (especially illicit/illegal) drug use, could reasonably be predicted before entering the field to collect data. To partially manage or overcome these issues the lead author's experience of training and competing in boxing was used to leverage some degree of acceptance as a 'cultural insider'. This enabled him to conduct 'observing participation' methods, which have been useful in previously exploring boxing gyms (de Garis 2010; Heiskanen 2012; Jump, 2017; Matthews, 2015, 2018; Paradis 2012; van Ingen 2011; Wacquant, 2004; Wright, 2018), to be used as a means of gaining initial access and developing somewhat trusting relationships with participants.

In Matthews $(2015,2018)$ the lead author considers a number of issues connected to conducting such 'insider' or 'involved' research. In employing such embodied research strategies (for example, observations and participant recruitment while training, sparing and 'hanging out' in boxing gyms - See Wellard (2015) for a broad discussion) it is possible to gain a relatively privileged closeness to the lives of boxers and experiences inside and around the ring. While 'becoming a boxer' (Matthews, 2018) certainly can provide possibilities for access and the sharing of experiences, which are of course useful methodologically, it is essential to consider that in maintaining a career as an academic there is a fundamental disjunction between the lead author's experience of boxing and the lives of most boxers. This includes, but is not limited to, his ability to withdraw from the subculture with ease, the different life chances afford him by his employment in contrast to the vast majority of boxers and his access to various means of identity formation beyond that of 'being a boxer' (Matthews, 2015, 2018). As such, no claims are made here to an enhanced authenticity based on such personal involvement in the sport, rather, these issues are discussed to provide the reader with an understanding as to how the participants were accessed and methodological tools which were drawn upon in this study. 
The data was obtained by combining observations in six boxing gyms (three on the South Coast and three in the East Midlands) and interviews with boxers and others involved in the sport who were based in various locations. The lead author spent two months training and collecting data in the gyms on the South Coast and three months doing similar in the East Midlands. There was no methodological justification for these times periods, rather, they aligned with 1) the time which was budgeted within funding constrains for the project and 2) the lead author's teaching commitments. Two and three months might be considered as a relatively short period of time to gain acceptance within social spaces, that said, the lead author's knowledge of and embodied proficiency in the sport certainly aided his ability in this regard. The goal during these observations was to get a 'feel' for the likelihood to drug use within the gym before recruiting participants who might be able to discuss such issues.

Training in the gym gave the lead author access to experiences such as witnessing discussions and usage of supplementation, seeing athletes manage illness and poor health, and hear discussions around training to develop (enhance) performance. Such observations could then provide useful start points and/or areas for clarification within interviews. As the research was conducted in the summer, a traditionally quite time for boxing gyms, it was necessary to widen the sample to ensure the findings would provide useful insights. Therefore, after some initial success in gaining access to boxing gyms, coaches and athletes, a snowball sampling method was used to help increase the number of participants.

Given that the central themes in this project could be handily explored using discursive methods, the lead author interviewed 25 participants, all of whom were either competing amateur boxers, had formally competed in amateur boxing, regularly trained in an amateur boxing gym, coached amateur boxers or were the guardians of amateur boxers. The interviewees included 23 men (21 self-identified as white British, two as mixed-race British) and two women (both self-identified as white British) aged between 18 and 62. Importantly, no broad claims of generalisability are made basis of this sample. What this sample does provide, however, is a window through which it is possible to begin to explore drug use in amateur boxing, and one which can help identify key issues to inform pathways for further, more systematically structured follow-up studies.

Initially a semi-structured interview approach was used for its targeted yet flexible nature (Gray, 2014), after approximately 10 interviews the lead author relied on the interview schedule less and instead encouraged conversations around performance enhancing and supplement and drug use. In this respect, while every interview centred on similar themes, each took a slightly different direction as conversations developed based on the participants own unique experiences and perspectives. In addition, the researcher also chatted informally with several of the participants before, during and after training sessions. When combined with field notes, observations and the lead authors background in the sport, these informal chats provided valuable additional insights which helped to inform conversations during the more formalised interviews.

The interviews, which were often conducted inside boxing gyms during quiet times, or in public spaces such as cafés that could still offer the necessary privacy, were recorded on a digital device with the consent of interviewees, and subsequently transcribed at the earliest opportunity. While an effort has been made to include details of the participants' biography in order to provide some context, it has been necessary to restrict such data in places to reduce the potential of participants being identified, this has of course included assigning each interviewee with a pseudonym. 
The transcribed interviews were subjected to a thematic analysis (Sparkes and Smith, 2014) and categorized into salient and theoretically informed themes. As no research has currently been published on supplement and drug use in boxing, it was decided that these empirical themes should be drawn out from the analysis. As such, the following findings section is organised in order to frame data on; recreational drugs, supplements and performance-enhancing drugs. Weaved within this structure is evidence which relate to the participants understandings and negotiations of ideologies of performance and pugilistic amateurism. So while the paper provides a useful empirical contribution, running alongside this is a number of findings that can be illustrative of wider theoretical explanations which frame discourses and behaviours that are commonplace within boxing gyms.

\section{Recreational Drug Use}

While recreational drug use ${ }^{4}$ was not an extant focus for this study at the outset, it became apparent within the first few interviews that when participants were questioned broadly about drug use they would either 1) interpret this as being asking about recreation drugs use, or 2) make comments which drew on their understanding of boxing's role in helping young people avoid or desist illegal and legal drugs. This section sketches out the manner in which a focus on performance ideologies, aligned with ways of considering the boxing body, shaped the way that recreation drugs are considered within somewhat isolated boxing havens. As such, it acts as a contextual point of departure for the theoretical dimensions of the paper, which is developed further in the sections on supplement and performance-enhancing drugs use.

Many of the participants had come into contact with recreational drugs themselves or via their friends and family. This was largely discussed by the participants as being correlated with the age and social-economic status of the population from which boxing tends to draw its participants. Take John' $\mathrm{s}^{5}$ discussion of marijuana as an example:

Yes, as I say, it's rife... We've got at risk kids that come in because of these things, but equally, we've got kids who, because they're at that age group, have tried it while they've been training, obviously. The handy thing is they're not too bright and it absolutely stinks. You can smell it on them.

Wayne ${ }^{6}$ described something similar:

I'd think that the majority of the lads down here have had the opportunity to do drugs, you know they can get hold of pills [ecstasy] easier than booze most of the time, nothing new though is it, I'm sure it was the same when you was growing up.

There was a partial acceptance that, due to the communities and age groups that have traditionally been associated with boxing, experimentation with recreational drugs was relatively common. Drawing on his experience competing, Daniel ${ }^{7}$ suggested that he had:

... heard of boxers that do drugs, whether it be soft drugs or class A drugs, you've heard of it. You know, boxers typically don't seem to be, don't tend to be angels.

\footnotetext{
${ }^{4}$ it is important to note that no judgment is made by either Matthews of this paper as to the legitimacy or otherwise of drugs use. Rather, we foreground the participants understandings which tended towards a negative interpretation.

${ }^{5}$ Is in his 40 s and coaches at a boxing club in the South West of England. He boxed while at school but gave it up due to illness, was formally a police officer and maintains links between the local force and his boxing club.

${ }^{6}$ Is a former competing amateur boxer in his 30 s who does some part time coaching so stay connected to the sport. He currently runs his own plumbing company and often helps out at the club when they need things fixing.

${ }^{7}$ Is in his 30s and coaches at a club in the South East of England. He boxed for over ten years and had over 40 bouts.
} 
A lot of them do come from that kind of, without sounding too PC, that kind of working-class background where it's a bit more prevalent, perhaps.

This pragmatic acceptance of the realities of recreational drugs was usually accompanied by the idea that involvement in boxing was a potentially powerful way of helping people reduce, or avoid, using such drugs. This was understood by the participants as especially prescient and effective for boys and young men. A similar case can of course be made of involvement in other sports and physical activities, notwithstanding this, a number of participants discussed how boxing had helped them in this regard:

At that particular time for me I just completely abstained from the use of any form of drug, a large part of which was because I was so focused on my boxing. It was more of a detractor and it kept me away from drug usage, rather than introduced me to it in any way. (Simon $\left.{ }^{8}\right)$

I used to smoke a bit of weed, but that soon stopped when I got out worked [in a fight] a few times. I remember [coach] telling me I needed to get fitter, I needed to do more sprints and that, but all I was thinking was stop fucking smoking ya ballbag. (Callum ${ }^{9}$ )

Here, Simon and Callum, are echoing a well-rehearsed narrative about boxing helping young people to break from potentially destructive behaviours (see Jump (2017) for a more broad discussion). In particular, the focus was on the manner that recreational drugs might affect their physical performance in the ring.

In a similar way, the coaches who were interviewed all had stories to tell about the transformative potential of boxing, the following conversation with Gary ${ }^{\mathbf{1 0}}$ was typical of such responses:

Matthews: Have you ever heard of this idea of people, [pause] boxing as a deterrent [for drugs], have you heard of anything like that?

$100 \%$. The world I work in, it's prolific, again sounds too strong, but it's relatively prolific. The families, there's a lot of drugs related issues and that's definite, that's fact, it's not hearsay, it's fact... The drugs that are available, it's easy for the young people to access. I've got a lad who comes down here with me, he came down for the first three terms, he's going somewhere else now, he was open in saying that boxing was a deterrent, the actual training, keeping fit, was a deterrent because he could use that as an excuse with his peers, not to get hammered, not get pissed, not to take drugs, not to smoke weed. He could say, 'I can't, I'm going training'. That's factual. I've got case studies. That's not a one off, I've got several lads who will say that. I'm not saying they can sustain keeping clean and staying off the drugs, there's so much pressure, peer pressure and family pressure, etc. They acknowledge and they know that they could use boxing as a deterrent, as an escape from that world.

\footnotetext{
${ }^{8}$ Is in his 20 s and had a small number of amateur bouts when he was young. He has but stayed involved in boxing as a coach and works in sports development.

${ }^{9}$ Is from the South East and is in his late teens. He is currently competing at the regional level while studying at college.

${ }^{10}$ Is a coach at a boxing club in the South East of England in his 40 s. He also uses the sport at schools with children with behaviour and emotional difficulties. He had over 40 fights in a variety of combat sports.
} 
It's all about respect. Respect for ya elders and doing what they say, but also respect for ya'sen; controllin' ya weight, being sharp, and listen to instructions, these things can't be done with drugs and booze in ya system. They learn that, often the 'ard way, and they learn to value themselves more and their ability to get it [the required physical work to be a boxer] done in the gym.

Through such discussions of the lessons that are learned alongside boxers training, we can see the manner in which the body and its physical performance is central to how the interviewees understood the sports place in helping people avoid recreational drugs. The body, and in particular, it's instrumental capacities of fitness, stoic resilience, speed and power, was understood by the interviewees to be hindered by recreational drugs and the lifestyles that accompanied them. This, in turn, could act to undermine the boxers' abilities to embody the traditional symbolic performance of working-class manhood that often dominate such space (Matthews, 2014, 2016, Woodward, 2007).

While such stories were commonplace and fit with the traditional narrative that boxing gyms can provide a space were, usually male, working-class, youths can escape some of the risks of ghettoised urban areas, the boxing coaches, were certainly not blind to the romanticism of such ideas. They understood these stories combined with their appreciation of boxing could bias their opinions about what involvement in the sport could achieve, yet, they were also quick to recount various success stories. For example, when Tom ${ }^{12}$ was asked about boxing gyms being seen as havens, he answered echoing key ideas from Hughes and Coakley's (1991) classic work:

I suppose people that support boxing have got to say that, it's this notion of it providing you with a sense of discipline and sacrifice etc., so it's true to say that recreational drugs and alcohol is anathema to the level of competition that you've participated in. Any kind of level of boxing competition that you've participated in there's an intensity associated with it but it tends to be anathema. For the few that persist it doesn't make sense to take recreational drugs and box. Out of a hundred very good boxers you should probably think that a large percentage of those guys don't do what other kids and their peers do as well.

All the participants identified this discourse; each attached various degrees of success to it. While such claims are often made of others sports the interviewees all thought that boxing had some special qualities that set it apparent from such examples. Here, connections to working-class communities, where recourse to drug use was understood by those in this study as particularly problematic, was an important factor.

The notion of boxing clubs as a type of haven or island partially isolated from the pressures of life outside the gym walls, as outlined by Wacquant (2004) and embedded in other's works (Matthews, 2014, 2016; Woodward, 2007), also opens up the possibility of such spaces acting as shelters to hide or obscure damaging and dangerous behaviours (see Crabbe (2000) for a discussion around a similar point using data from football). Take the following example from Simon who suggested that:

I think there's a very strong community ethos within a boxing club, which could serve either in favour or preventing [drug use] or in favour of enforcing it. There was one particular club which this individual was involved with as a secretary or a volunteer within it, and [the person] said that there were drug users, or rather

\footnotetext{
${ }^{11}$ Is in his 50s and oversees coaching in a boxing club in Lincolnshire, he's worked in public services since his early 20 s

12 Is in his 30s and lives in the midlands. He started boxing as a teenager and had trials for youth national squads. He know works in higher education and hopes to use boxing to help some of his students.
} 
the coaches and some of the other volunteers were dealing drugs in a back room, away from the kids.

Alongside such a dramatic story came a pragmatic realisation from the interviewees that boxing was not a panacea to cure all societies problems. The majority of the participants had a clear understanding that the sport had limited potential in this regard. John stated that:

Well, it goes either of two ways. "I either want that or I want something that's more significantly productive, which is this". I'm not going to sit here Chris, and say it's all things to all men and the answer to everything. It's not. We lose probably as many as we gain, because some of them you simply will not reach, and a lot of that is, as I say, peer pressure.

Echoing Crabbe's (2000) discussion of the potential disillusion and alienation that can accompany not 'making the grade' in sport, some of the participants also discussed the potential that frustration with the sport or lack of success could lead boxers towards a rejection of the performance ideology and the discipline this promotes in favour of experimentation with recreational drugs:

I've never been into that but some of the lads down here are. It's usually when they get pissed off with training or if they lose or something, like most of our mates do loads of drugs so it's really easy to get into if you get pissed off with it all. (Carl13)

Such ideas align neatly with Hughes and Coakley's (1991) discussion of underconformity to the 'sports ethic' whereby they propose a rejection of the central norms of performance sport can result in athletes taking recreational drugs. The majority of interviewees were reflective enough to appreciate that participation in boxing did not automatically ensure young people would resist temptations to experiment with recreational drugs. Yet, it was clear that the focus on performance outcomes, which were shaped by an instrumental, working-class understanding of the male body, was believed in most cases to enable boxers to resist engaging in behaviours that might be detrimental to their develop as boxers. Here, then, there is some evidence that points tentatively to boxing gyms acting as havens where a focus on performance and selfimprovement, given meaning by traditional notions of a working-class, masculine orientation to the body, might enable some people to negotiate social pressures to use and/or abuse recreation drugs.

\section{Supplement Usage}

While the use of recreational drugs largely represents a rejection of the central norms of performance sport (Hughes and Coakley, 1991), the use of supplements to enhance recovery and physiological development appears to neatly resonate and align with them. According to Hughes and Coakley (1991), being involved in elite sport demands athletes make sacrifices for 'The Game', strive for distinction, accept risks, play through pain and refuse to accept physical limitations, as such, seeking various advantages through the use of supplementation logically 'fits'. Yet, within boxing spaces this process also plays out in relation to pugilistic amateurism.

\footnotetext{
${ }^{13}$ Is in his 20s, he has been involved in boxing since before he was ten but only had a small number of fights. He is currently unemployed and looking to attend a vocational course at a local college.
} 
In this regard, the notion of boxing as "kinda old school" (Kev'14) was repeatedly discussed as an explanation for the way in which supplementation was approached in gyms. So while the central features of the sport might align well with the performanceorientated norms that Hughes and Coakley (1991) describe, there was a distrust and often-outright rejection of the need for supplementation in favour of what was considered a more authentic and effective form of enhancing performance, which was infused with a focus on personal development. Kev told me the following:

I just don't think they [boxers] need it, especially the young ones. What they need is to learn how to look after themselves properly, you won't hear any of the coaches talk about [supplements] in here, but they do tell them to eat properly and get to bed at a proper hour.

Tim ${ }^{15}$, said something similar, and reeled out his advice as if he was saying it for the millionth time, "...they don't need non of that crap in their bodies, we teach 'em the proper ways here; graft, food, rest, repeat. That'll give ya everything ya need". While such ideas were clearly a dominant narrative, those who operated towards the elite level of the sport appeared to be more accepting of the need to embrace sports science and nutritional knowledge. Yet, it was clear that these discussions had to make sense of the traditional rejection of supplements within boxing gyms. The following extras from interviews with Mark ${ }^{16}$ and Daniel are illustrative:

That is coming a lot more into it now. I think it's had a bad rep in the past. You know, people taking protein supplements and, you know, vitamin supplements, stuff that they've maybe found online. Maybe five years ago, it was kind of looked at as something you definitely didn't do, but it's actually, I think people are becoming more educated about it now, and understanding that there are actual benefits to the fuelling, the performance, the recovery part of training. So, it's becoming, I think a little bit more less tabooed, because people are getting educated. It's not coming under that kind of that umbrella of achieving benefits unfairly. (Mark)

People are starting to understand it and use it a lot more and, you know, me as a coach as well, I started to understand the gains, in terms of the fuelling, performing and recovery as well. So, I'm starting to almost lament it a little bit more to the boxers, whereas five years ago, I said, 'No, you don't need that crap. Just make sure you eat well. You train well. You rest well.' That kind of thing, but now some of it does help you give you that extra, a little bit more competitive when they've eaten. (Daniel)

Here, both men noted the shift away from the 'old school' towards an embracing of newer methods informed by a focus on performance, however, this was still shaped by and articulated in dialogue with ideas from pugilistic amateurism.

Furthermore, the interviewees who had these more positive orientations towards supplement usage either had personal experience of studying sport science and physical education or had a connection to such disciplines via other coaches or colleagues. Tom discussed how his education made him more receptive to supplements:

\footnotetext{
${ }^{14}$ Is former amateur boxer who is in his early 40 s. He now brings his two boys down to train at a local boxing club. He works as an alarm fitter and still does some boxing but mainly at home on his own punching bag.

${ }^{15}$ Is a former amateur boxers in his 60s who has ran a small gym in the West Midlands for over 20 years.

${ }^{16}$ Is a boxing coach in his mid 30s. He started coaching after retiring from amateur boxing at 17 . He also works as a

football coach and splits his time between the two sports.
} 
My experience was that I was doing Sport Studies at [a local university] and I was fairly receptive of that and I started to develop my understanding. I think creatine was a big thing at the time, I kind of experimented with creatine, but my experience was that it bloats you and that's not what I wanted to achieve. My optimum weight was nine stone four so it was just the very old-fashioned techniques of hard graft, sweating as much liquid out as possible. I believe they've changed now, the boxers, particularly at high end they've got a savvy way about things. Saying that, MaxiMuscle, I would take carbohydrate supplements and then was straight off on my runs. I remember experimenting with a substance called acetylglutamate before I used to go in the ABAs, they were just, you can buy it off the shelves but I could feel it in my system, particularly when I used to make weight, it seemed to aid my recovery, even psychologically. That worked for me but at one stage it just stopped appearing on the shelf, you couldn't get it from the catalogue so I'm wondering if that crossed the boundaries of legality.

This is a clear example of Maguire's (2004) discussion of one dimension of the sportsindustrial-complex whereby ideas from the performance orientated sports science align with the performance ideologies to shape the ways athletes consider themselves, their bodies and their participation in sport. And while narratives which draw on pugilistic amateurism might offer some resistance to such ideas dominating boxing gyms, this was not always the case for some athletes as Peter described of one of his boxers:

Everybody, especially these kids, and me, everybody has people that they aspire to be, be it a peer, be it somebody famous, you know, if they said a spoonful of camel shite a day would improve your performance, they will take it. There's no two ways about it. We've got one who is just absolutely hell bent, he will make it no matter what, to the point he's put himself in hospital before now, because he's just completely over-trained. Yes, it's a worry Chris, because yes, they're impressionable.

In summary, most of the participants highlighted the importance of 'old school' ideas, which aligned with pugilistic amateurism, in resisting the shift towards supplementation as a means of increasing performance. The evidence presented here show that this process was worked out in different spaces in different ways, however, when similar discussions moved towards illicit performance enhancing drugs, the discussions followed a more clear path.

\section{Performance-Enhancing Drug Usage}

The preceding sections have not only detailed data about the manner in which recreation drugs and supplements are understood within boxing spaces, they have also helped to outline the social context within which boxers, coaches and others connected to the sport operate. In particular, they have provided insight into the ideological terrain within which boxers exist. This context helps to make sense of the data which was collected about performance-enhancing drugs. The participants overwhelmingly suggested that such drug use "wasn't really a thing in [amateur] boxing" (Peter ${ }^{17}$ ). Daniel suggested the following:

I never saw anything of that in my gym. Knew nothing of that. Never heard of it. As a coach, again, I, it's almost whether I'm, I've just had my head down and

\footnotetext{
${ }^{17}$ Is a former amateur and professional boxer from Yorkshire in his 40s. He prefers running to boxing as a means of staying fit but he stays involved with a couple of local clubs through his contacts in boxing.
} 
never noticed or it's never happened, but I think it was probably the latter. I've never run into it. (Daniel)

Embedded within the participants responses, particularly the coaches, were claims aligning with the notion of boxing clubs being havens where performance-enhancing drugs simply would not be tolerated. In a quite emphatic response, Tim told me during a chat in the gym he founded: "this is a place where you just don't get it. No one seeks any of that sort of stuff, no one knows about it, no one would consider putting that shit in their bodies".

When pushed as to why this was the case the majority of the participants drew on ideas that were informed by pugilistic amateurism, in particular, that boxers are socialised into working hard for success and that drug use represented a rejection of that idea. Casey's $^{18}$ response was fairly typical:

I just don't see it. Stuff like that was always seen as a sign of weakness, you work for your success in boxing, there's no cutting corners really, it's like-, that's one of the things they instil in all the youth, that's one of the reasons I think it just hasn't crept into our sport yet.

The explanation offered by Casey, and the other boxers and coaches was that the traditional ways of training and competing in amateur boxing make the sport resistant to performance enhancing drugs use. While such ideas echo some of the, widely critiqued, mythologised and moralistic discussions about the power of sport to do social and personal good, the participants each had multiple stories and personal experiences which lead them to give these ideas credence.

Indeed, Rachel ${ }^{19}$ suggested that there was an expectation within the club that she took her daughter to that young athletes would clearly place their schooling ahead of boxing, and that, as such, drugs use simply did not make sense:

Boxing's just not like that, don't take this the wrong way but it's not professional enough, to be honest, that's why I like [daughter] doing it, because they have to make a commitment to it, but it's never too much, it's never more important than school. Sometimes, I think sports clubs just take it too far and get too serious, but from what I know of boxing it's just not like that.

Here, the amateur ethos was equated with a reasonable understanding of the place that sports should occupy in young people's lives. Therefore, the over-conformity to social norms that Hughes and Coakley (1991) argue dominate performance-orientated sport, which can logically encourage drugs use, was through to be undermined. And in its place was an understanding that there were important life lessons and opportunities for personal development that were embedded within participation in boxing.

One of the associated themes that participants also drew on was the lack of money in the sport and the economic background of the participants. Barry ${ }^{20}$ suggested, "they can't afford it most of them, and even if they start winning 'cause of taking [performance enhancing drugs] there just isn't the financial reward to make it worthwhile". This

\footnotetext{
${ }^{18}$ Is a barber from the midlands in his 20s. he topped boxing competitively after around six fights due to work commitments. He still likes to train and spar at his club, but also enjoys golf and lifting weights.

${ }^{19}$ Is a teacher in her 30 s from the midlands. She started bringing her daughter to boxing classes after taking up the sport herself.

${ }^{20}$ Is a former amateur and professional boxers in his 40s who now owns a gym and organises some white-collar boxing events.
} 
financial issue led a number of the participants to highlight a difference between the amateur and professional codes:

In amateur boxing, I've never really heard of it to be honest. I've never heard of anything, you know, that you hear in the press like anabolic steroids this, or sports performance enhancing that. I've never seen it, I've never heard of it. Not to say that it doesn't go on I'm sure, but it seems to be more something that is kind of pushed almost as a part of the pro-game. You hear about people miraculously making weight or people developing freak strength in short periods of time, but the amateur game, no. I've never heard of it, to be honest. (Daniel)

The symbolic line between amateur and professional boxing is drawn somewhat arbitrarily. Some amateur boxers aspire to 'turn pro' and it is not uncommon for amateurs to train with professional athletes. Yet, this symbolic difference was certainly important to the participants and it helped them make sense of performance-enhancing drugs as illegitimate and simply not a part of their 'game'.

Furthermore, Tom highlighted that the changing structure of elite amateur boxing might make the traditional distinction between amateur and professional boxing increasingly problematic, "in the present day you've got those high-performance amateurs now that are fully professionalised, aren't they? ... they're almost super amateurs". John also suggested that performance enhancing drugs use was an issue that might be occurring towards the elite level of the sport, he discussed his suspicions that someone was using the band substance Erythropoitin (EPO):

EPO, yes. There's a top-level boxer and we were absolutely convinced, [another coach] will know as well, I'm not even going to mention the name on that. Fortunately, in the 30-odd years I've been involved, it was just that one incident. Predominantly, it's a gross generalisation, but I would suspect it mainly is the male senior elite that this would happen.

Considering the media attention that is currently focused on drugs use in sport it is perhaps somewhat surprising that this was the only suspicion of doping to be discussed during the interviews. While it is important to be wary when drawing conclusions from such a limited sample, this data certainly suggests that the narratives about boxing and codes of conduct that tend to be popular inside gyms and boxing communities might have a role to play in reducing the likelihood of drug use. We have presented data to support this claim while also sketching out how ideas connected to pugilistic amateurism are an important part of this process. In particular, the ideological tension between such 'old school' thoughts about training, the body and participation in sport, were mediated by, and played out within, boxing gyms which acted as partial havens where such narratives could exist despite being largely undermined outside of the gym's walls.

\section{Concluding Remarks}

Within the preceding section we have attempted to lay out how people associated with amateur boxing thought about performance-enhancing drugs use. By considering the manner in which they repudiated performance ideologies using notions informed by pugilistic amateurism we have sought to present empirically noval and theoretically useful findings. So, while Wadler $(2009,542)$ dismissively assumes that there "is nothing in the sport of boxing that makes it immune from doping", we have drawn on existing research and lived experiences to provide a more nuanced and theoretically robust understanding. Specifically, we have argued that key literature on the topic 
points to the potential for boxing gyms to offer gym denizens the ability to resist performance ideologies that dominate other sports. Here, the sports connection to amateurism and traditional working-class, masculine values of putting in 'honest' hard work without cutting corners enabled coaches and athletes to reframe the extant purpose of the sport away from a 'win at all costs' mentality. In this way, the participants could develop and reinforce an instrumentive understanding of the body which negotiated and/or subverted key assumptions from the performance ideology that dominates sport.

Furthermore, we have highlighted the manner which boxers were able to employ narratives shaped by a performance ideology to help them avoid recreational drug use. While boxing is clearly not a panacea which can simply solve individual and community problems, there is some evidence that points to the potential for the sport to be useful in enabling participants to shift their focus away from potentially damaging social norms which dominate life outside the gym. In this regard, boxing gyms were thought by those involved in this study to operate somewhat like 'havens' which gave boxers the opportunity to remove themselves from otherwise chaotic or harmful social worlds. And in considering how such spaces mediated notions connected to pugilistic amateurism we have gone some way to fleshing out the sports potential in this regard.

Importantly, those interviewed in this study did not simply reject or align with performance ideologies. Rather, they negotiated them in relation to understandings of a pugilistic amateurism. This process helped them to draw on apparently positive dimensions of focusing on performance while also avoiding an uncritical, ideological acceptance of this way of being involved in sport. Safai (2003) discusses a similar process of negotiation researching student athletes whose participation in sport was situated within 'cultures of risk' and 'cultures of precaution'. Here, a focus on performance ideologies was in part tempered by a need to maintain and attend to health and wellbeing. So while elite sports are saturated in an "athletic achievement and performance improving ideology" (Stewart and Smith 2010, 195), Safai's argument, and that presented here, demonstrates that under the right conditions athletes and coaches can draw on alternative narratives to help them resist the most damaging effects of a blinkered focus on performance. It is within such a process that we argue it is possible to evidence some of the positive personal and social outcomes that can accompany participation in sport.

The empirical findings and theoretical scaffolding presented in this work add weight to Henning and Dimeo's $(2018,134)$ discussion of the important differences between professional and amateur sport in relation to doping. And, as such, we agree with their conclusion that:

... amateurs are different from elites in their levels of competition but also in their motivations for engaging in sport and their reasons for using banned substances... It follows that anti-doping should not approach amateurs in the same that it has elites.

Furthermore, we have demonstrated the potential that is embedded in sports participation for athletes to resist and negotiate performance ideologies. Future research should main conceptual space for such contestation to ensure the lived realities of athletes' understandings of doping can be more fully understood. And more wor should be conducted to further explore the manner in which pugilistic amateurism shapes gym life at various levels and in interactions with other social narratives and ideological pressures. 


\section{References}

Alison, L. (2001) Amateurism and Sport. London, Routledge.

Baron, D.A., Martin, D.M. and Magd, S.A. (2007) Doping in Sports and its Spread to AtRisk Populations: An International Review. World Psychiatry, 6(2), 118-123.

Beamish R. and Ritchie, I. (2004) From Chivalrous 'Brothers-in-Arms' to the Eligible Athlete - Changed Principles and the IOC's Banned Substances List. International Review for the Sociology of Sport, 39(4), 355-371.

Beamish R. and Ritchie, I. (2005) From Fixed Capacities to Performance Enhancement: The Paradigm Shift in Science of 'Training' and the Use of Performance-Enhancing Substances. Sport in History, 25(3), 412-433.

Boddy, K. (2009) Boxing: A Cultural History. London, Reaktion Books.

Brohm, J.M. (1976) Sport - A Prison of Measured Time (Trans. I. Fraser). London, Ink Links.

Channon A. and Matthews, C.R. (2015) Global Perspectives on Women in Combat Sports: Women Warriors around the World. Basingstoke: Palgrave Macmillan.

Channon A. and Matthews, C.R. 2018. Love Fighting Hate Violence: An Anti-Violence Program for Martial Arts and Combat Sports. In, T.F. Carter, D. Burdsey and M. Dodge, (Eds.), Transforming Sport: Knowledges, Practices, Structures. Abingdon: Routledge.

de Garis, L. (2000) 'Be a Buddy to Your Buddy'. In J. McKay, M. Messner and D. Sabo (Eds.) Masculinities, Gender Relations and Sport. London, Sage.

de Garis, L. (2010) Sometimes a Bloody Nose is Just a Bloody Nose: Play and Contest in Boxing, Wrestling, and Ethnography. Sport in Society, 13(6): 935-951.

Coomber, R. (2014) How Social Fear of Drugs in the Non-sporting World Creates a Framework for Doping Policy in the Sporting world. International Journal of Sport Policy and Politics, 6(2), 171-193.

Crabbe, T. (2000) A Sporting chance? Using Sport to Tackle Drug Use and Crime. Drugs: Education, Prevention and Policy, 7(4), 381-391.

Dimeo P. (2007) A History of Drug Use in Sport: 1876-1976: Beyond Good and Evil. London, Routledge.

Dimeo, P. (2010) Understanding and Managing Drugs in Sport. The Shield: Research Journal of Physical Education \& Sports Science, 5

Downing, K. (2010) The Gentleman Boxer: Boxing, Manners, and Masculinity in Eighteenth-Century England. Men and Masculinities, 12(3): 328-352. 
Fulton, J. (2011) 'What's Your Capital Worth?' - The Development of Capital in British Boxing. European Journal for Sport and Society, 8(3): 193-218.

Gray, D. E. (2014) Doing Research in the Real World [3 ${ }^{\text {rd }}$ ed.]. London, Sage.

Gleaves, J. and Hunt, T. (2013) A Global History of Doping in Sport: Drugs, Policy, and Politics. Routledge, London

Halbert, C. (1997) Tough Enough and Women Enough: Stereotypes, Discrimination, and Impression Management Among Women Professional Boxers. Journal of Sport and Social Issues, 21(1): 7-36.

Hargreaves, J. (1986) Sport, power and culture. A social and historical analysis of popular sports in Britain. Oxford, Polity Press.

Heiskanen, B. (2012) The Urban Geography of Boxing: Race, Class, and Gender in the Ring. London: Routledge.

Henning, A.D. (2014) (Self-)Surveillance, Anti-Doping, and Health in Non-Elite Road Running. Surveillance Society, 11(4), 494-507.

Henning, A.D. (2015) Health Culture and Running: Non-Elite Runners' Under-Standings of Doping and Supplementation. Journal of Amateur Sport, 1(2), 51-77.

Henning, A.D. and Dimeo, P. (2018) The New Front in the War on Doping: Amateur Athletes. International Journal for Drug Policy, 51, 128-136.

Hoberman, J.M. (1992) Mortal engines: The science of performance and the dehumanization of sport. Free Press, New York

Holt, R. (1989) Sport and the British. Oxford, Oxford University Press.

Houlihan, B. (2002) Dying to Win: Doping in Sport and the Development of Anti-Doping Policy. Strasbourg: Council of Europe Pub..

Hughes, B., and Coakley, J. (1991) Positive Deviance Among Athletes: The Implications of Over Conformity to the Sports Ethic. Sociology of Sport Journal 8(4), 307-325.

Jefferson, T. (1996) Mike Tyson - Subjectivity and transformation. In Mairtain Mac an Ghail (Ed.). Understanding Masculinities - Social Relations and Cultural Arenas.

Buckingham: Open University Press.

Jennings, L.A. (2015) She's a Knockout! A History of Women in Fighting Sports. London: Rowman and Littlefield

Johnson, M.D. (1990) Anabolic Steroids use in Adolescent Athletes. Paediatric Clinics of North America, 37, 1111-1123.

Johnson, J. Butryn T. and Macucci, M.A. (2013) A Focus Group Analysis of the US and Canadian Female Triathletes Knowledge of Doping. Sport and Society, 16(5) 654-671.

Jump, D. (2017) Why we Should Think Some More. A Response to 'When You're Boxing You Don't Think so Much': Pugilism, Transitional Masculinities and Criminal Desistance Among Young Danish Gang Members. Journal of Youth Studies, 20(8), 1093-1107. 
Lafferty, Y. and McKay, J. (2004) 'Suffragettes in Satin Shorts'? Gender and Competitive Boxing. Qualitative Sociology, 27(3): 249-276.

Laure, P. and Binsinger, C. (2007) Doping Prevalence Among Preadolescent Athletes: A 4-Year Follow Up. British Journal of Sports Medicine, 41: 660-663.

Lentillon-Kaestner V., and Ohl, F. (2010) Can We Measure Accurately the Prevalence of Doping? Scandinavian Journal of Medicine and Science in Sport 21(6), 132-142.

Lun, V., Erdman, K.A., Fung T.S. and Reimer R.A. (2012). Dietary Supplementation practices in Canadian High-Performance Athletes. International Journal of Sport Nutrition and Exercise Metabolism, 22(1), 31-37.

Maguire, J. A. (2004) Challenging the Sports-Industrial Complex: Human Sciences, Advocacy and Service. European Physical Education Review, 10(3), 299-321.

Malcolm, D. (2016) Sport, Medicine and Health: The Medicalization of Sport? Routledge, London.

Matthews, C. R. (2014). Biology Ideology and Pastiche Hegemony. Men and Masculinities, 17(3) 17(2), 99-119.

Matthews, C.R. (2015) Being Nosey - The Body as an Effective by Flawed Tool for Research. In I. Wellard (Ed.) Researching Embodied Sport - Exploring Movement Cultures. London: Routledge.

Matthews, C. R. (2016). The Tyranny of the Male Preserve. Gender and Society, 30(2), 312-333.

Matthews, C.R. (2018) On (Not) Becoming: Involved-Detachment and Sports Violence. In, D. Malcolm and P. Velija, (Eds.) Figurational Research in Sport, Leisure and Health. Abingdon, Routledge.

Matthews, C.R., (2019). Becoming a "decent Man" Learning Through Boxing. In, N. Barker-Ruchti (Ed.) Athlete Learning in Elite Sport: A Cultural Framework. Abingdon, Routledge.

Matthews, C.R. and Channon, A. (2016). 'It's Only Sport': The Symbolic Neutralisation of 'Violence'. Symbolic Interaction, 39(4), 557-576.

Matthews, C.R. and Channon, A. (2017) Understanding Sports Violence: Revisiting Foundational Explorations. Sport in Society, 20(7), 751-767

Matthews, C.R. and Channon, A. (2019) The 'Male Preserve' Thesis, Sporting Culture, and Men's Power. In L. Gottzén, U. Mellström and T. Shefer, Routledge Handbook of Masculinity Studies. London, Routledge.

Matthews, C.R. and Maguire, J., 2019. Sports, violence, and society: some sociological observations. In: J. MAGUIRE, M. Falcous and K. Liston, eds., The business and culture of sports: society, politics, economy, environment. Vol. 2, Sociocultural perspectives. Farmington Hills, MI: MacMillan Reference USA, pp. 113-125.

Møller,V., Waddington, I. and Hoberman J.M. (2016) Routledge Handbook of Drugs and Sport. Routledge, London. 
Morente-Sanchez, Mateo-March and Zabala, (2013) Attitudes Towards Doping and Related Experience in Spanish National Cycling Teams According to Different Olympic Disapplines. PLoS ONE 8(8), e70999.

Mennesson, C. (2000) 'Hard' Women and 'Soft' Women: The Social Construction of Identities Among Female Boxers. International Review for the Sociology of Sport 35(1): 21-33.

Messner, M. (1990) When Bodies are Weapons: Masculinity and Violence in Sport. International Review for the Sociology of Sport, 25(3); 203-221.

Miah, A. (2004) Genetically Modified Athletes: Biochemical Ethics, Gene Doping and Sport. London, Routledge.

Ohl, F., Fincoeur, B., Lentillon-Kaestner, V., Defrance, J. and Brissonneau, C. (2015) The Socialization of Young Cyclists and the Culture of Doping. International Review for the Sociology of Sport, 5(7), 865-882.

Pappa, E. and Kennedy, E. (2012) 'It was my Thought... He Made it a Reality': Normalization and Responsibility in Athletes' Accounts of Performance Enhancing Drug Use. International Review for the Sociology of Sport. 43(3), 277-294.

Paradis, E. (2012) Boxers, Briefs or Bras? Bodies, Gender and Change in the Boxing Gym. Body and Society, 8(2): 82-109.

Rhodes, J. (2011) Fighting for 'Respectability': Media Representations of the White, 'Working-Class' Male Boxing 'Hero'. Journal of Sport and Social Issues, 35(4): 350-376.

Sas-Nowosielski, K. and Swiatkowske, L. (2007) The Knowledge of the World AntiDoping Code Among Polish Athletes and Their Attitudes Towards Doping and AntiDoping Policy. Human Movement, 8, 57-64.

Safai, P., 2003. Healing the Body in the 'Culture of Risk': Examining the Negotiation of Treatment Between Sport Medicine Clinicians and Injured Athletes in Canadian Intercollegiate Sport. Sociology of Sport Journal, 20(2), 127-146.

Schnieder, A.J. (2007) Cultural Nuances: Doping, Cycling and the Tour de France. Sport in Society, 9(2), 212-227.

Sluggett, B. (2011) Sport's Doping Game: Surveillance in the Biotech Age. Sociology of Sport Journal, 28, 387-403.

Sparkes, A.C. and Smith, B. (2014) Qualitative Research Methods in Sport, Exercise and Health: From Process to Product. Abingdon, Routledge.

Strano Rossi S. and Botre, F. (2011) Prevalence of Illicit Drug Use Among the Italian Athlete Populatiopn with Special Attenytion on Drugs of Abuse: A 10-Year Review. Journal of Sports Sciences 29(5), 471-476.

Striegel, H., Simon, P. and Frisch, S. (2006) Anabolic ergogenic substances users in fitness-sports: a distinct group supported by the healthcare system. Drug and Alcohol Dependence, 81, 11-19.

Stewart B. \& Smith, A.C.T. (2010) The Role of Ideology in Shaping Drug Use Regulation in Australian Sport. International Review or the Sociology of Sport, 45(2), 187-198. 
Sugden, J. (1996) Boxing and society: An international analysis. Manchester University Press, Manchester.

Sugden, J. and Tomlinson, A (2002) Power Games - A Critical Sociology of Sport. London, Routledge.

Tomlinson, A. (2005) Olympic Survivals - The Olympic Games as a Global Phenomenon. In L. Alison (Ed.) The Global Politics of Sport - The Role of Global Institutions in Sport. London, Routledge.

van Ingen, C. (2011) Spatialities of Anger: Emotional Geographies in a Boxing Program for Survivors of Violence. Sociology of Sport Journal, 28, 171-188.

van Ingen, C, and Nicole K. (2013) Subverting the Skirt: Female Boxers' 'Troubling' Uniforms. Feminist Media Journal, 12(3): 460-463.

Wacquant, L. (2004) Body and Soul: Notebooks of an Apprentice Boxer. Oxford: Oxford University Press.

Waddington I. (2016) Towards an Understanding of Drug Use in Sport - A Medical Sociological Perspective. In V. Møller, I. Waddington, J.M. Hoberman (Eds.) Routledge Handbook of Drugs and Sport. Routledge, London.

Waddington I. and Smith, A. (2009) An Introduction to Drugs in Sport. London, Routledge.

Waddington, I., Christiansen, A.K., Gleaves, J., Hoberman, J. and Moller, V. (2013) Recreational Drug Use and Sport: Time for a WADA Rethink? Performance Enhancement and Health, 2, 41-47.

Wadler, G.L. (2009) The Status of Doping and Drug Use and the Implication for Boxing. Clinics in Sports Medicine, 28, 533-543.

Wellard, I. (2015) Researching Embodied Sport: Exploring Movement Cultures. Routledge, London.

Woodward, K. (2007) Boxing, Masculinity and Identity: The 'I' of the Tiger. Routledge, London.

Woodward, K. (2008) Hanging Out and Hanging About: Insider/Outsider Research in the Sport of Boxing. Ethnography, 9(4), 536-560.

Wright, E. (2018) Fast-track Fisticuffs? An Ethnographic Exploration of Time and Whitecollar Boxing. International Review for The Sociology of Sport. Online first, https://doi.org/10.1177/1012690218815139

Young, K. (1993). Violence, Risk, and Liability in Male Sports Culture. Sociology of Sport Journal, 10, 373-396.

Young, K., White, P. \& McTeer, W. (1994). Body Talk - Male Athletes Reflect on Sport, Pain and Injury. Sociology of Sport Journal, 11, 175-194. 
